Article

\title{
Plasma Treating Mixed Metal Oxides to Improve Oxidative Performance via Defect Generation
}

\author{
Jonathan Horlyck ${ }^{1}$, Alimatun Nashira ${ }^{1}$, Emma Lovell ${ }^{1}$, Rahman Daiyan ${ }^{1}$, Nicholas Bedford ${ }^{1}$, \\ Yuexing Wei ${ }^{2}$, Rose Amal ${ }^{1}$ and Jason Scott ${ }^{1, *}$ \\ 1 School of Chemical Engineering, The University of New South Wales, Sydney, NSW 2052, Australia \\ 2 School of Energy and Environment, Southeast University, Nanjing 210096, China \\ * Correspondence: jason.scott@unsw.edu.au
}

Received: 1 August 2019; Accepted: 26 August 2019; Published: 27 August 2019

\begin{abstract}
The generation of structural defects in metal oxide catalysts offers a potential pathway to improve performance. Herein, we investigated the effect of thermal hydrogenation and low-temperature plasma treatments on mixed $\mathrm{SiO}_{2} / \mathrm{TiO}_{2}$ materials. Hydrogenation at $500{ }^{\circ} \mathrm{C}$ resulted in the reduction of the material to produce $\mathrm{Ti}^{3+}$ in the bulk $\mathrm{TiO}_{2}$. In contrast, low temperature plasma treatment for 10 or 20 min generated surface $\mathrm{Ti}^{3+}$ species via the removal of oxygen on both the neat and hydrogenated material. Assessing the photocatalytic activity of the materials demonstrated a $40-130 \%$ increase in the rate of formic acid oxidation after plasma treatment. A strong relationship between the $\mathrm{Ti}^{3+}$ content and catalyst activity was established, although a change in the $\mathrm{Si}-\mathrm{Ti}$ interaction after plasma treating of the neat $\mathrm{SiO}_{2} / \mathrm{TiO}_{2}$ material was found to limit performance, and suggests that performance is not determined solely by the presence of $\mathrm{Ti}^{3+}$.
\end{abstract}

Keywords: silica-titania photocatalysts; defect generation; plasma pre-treatment; oxygen activation

\section{Introduction}

Noble metal-free catalysts have gained increasing attention as alternatives for a range of oxidation processes, such as the oxidation of carbon monoxide [1,2], methanol [3,4], toluene [5,6], and formaldehyde $[7,8]$. While metal oxide catalysts, such as $\mathrm{TiO}_{2}$ and $\mathrm{SiO}_{2}$, have the key advantage of being cheap and abundant, their performance towards catalytic oxidation remains lower than materials containing noble metals, such as Pt. Thus, improving the catalytic activity of metal oxides via tailored synthesis and pre-treatment methods is of significant interest.

The generation of defects in metal oxides has been shown to enhance numerous catalytic processes, for instance, in water splitting and charge storage [9], the oxygen reduction reaction [10], and carbon dioxide reduction [11]. While defects such as oxygen vacancies are induced naturally during the synthesis of many metal oxides, they can also be generated and altered via treatments such as high-temperature reduction [12,13], doping [14], and illumination [15]. From a photocatalysis perspective, the generation of surface defects in metal oxides acts to provide active sites for reactions, through the ability to trap holes or electrons, resulting in charge separation and facilitating oxygen activation $[16,17]$.

$\mathrm{TiO}_{2}$ is a reducible metal oxide which has been shown to readily form surface defects, such as $\mathrm{Ti}^{3+}$, via various pre-treatment methods [12,18]. In a previous study, defects in $\mathrm{TiO}_{2}$ prepared via flame spray pyrolysis (FSP) were induced by doping with $\mathrm{SiO}_{2}$, treating with $\mathrm{H}_{2}$ at $500{ }^{\circ} \mathrm{C}$, followed by UV-light pre-illumination [19]. The various pre-treatment methods led to the creation of $\mathrm{Ti}^{3+}$ in $\mathrm{TiO}_{2}$ and non-bridging oxygen hole centre (NBOHC) defects in $\mathrm{SiO}_{2}$. Ultimately, a synergism between these two defects, which was found to be dependent on the $\mathrm{Si} / \mathrm{Ti}$ ratio, governed catalytic performance towards the oxidation of formic acid. Similar to high temperature hydrogenation, plasma 
treatment can be used to modify a metal oxide, however, the generation of defects via plasma treatment occurs primarily at the material surface, rather than in the bulk [20]. The highly energetic discharge particles can modify the surface in a short time, especially compared to time-consuming thermal treatments, via charge transfer, sputtering, or deposition [21]. Reported research concerning the plasma treatment of $\mathrm{TiO}_{2}$-based materials primarily utilises high temperature or high power plasma [13,22-24]. In comparison, there is a distinct lack of knowledge regarding the effect of low-temperature plasma treatments on defect generation and the ensuing influence this has on the catalytic performance of mixed metal oxide systems, such as $\mathrm{SiO}_{2} / \mathrm{TiO}_{2}$. Furthermore, there is new knowledge to be gained by studying what effect using multiple defect-generating treatment methods in combination has on the properties of the mixed metal oxides.

In this work, we studied the generation of defects by the hydrogenation at $500{ }^{\circ} \mathrm{C}$ and/or low temperature plasma treatment of a mixed $\mathrm{SiO}_{2} / \mathrm{TiO}_{2}$ composite that was synthesized via FSP. The formation of $\mathrm{Ti}^{3+}$ defects during the hydrogenation and plasma treatments was systematically investigated with X-ray photoelectron spectroscopy (XPS), electron paramagnetic resonance (EPR), X-ray absorption spectroscopy (XANES, and EXAFS) analyses, with a link between material pre-treatment and the photocatalytic oxidation of formic acid established.

\section{Experimental}

\subsection{Mixed Metal Oxide Preparation}

Titanium isopropoxide (TTIP, Sigma Aldrich, St. Louis, MO, USA) and hexamethyldisiloxane (HMDSO, Sigma Aldrich) in absolute ethanol were mixed with molar concentration of $1.194 \mathrm{M}$ and $0.066 \mathrm{M}$, respectively, to give a Si:Ti molar ratio of 1:9. The precursor mixture was then used to prepare a mixed $\mathrm{SiO}_{2} / \mathrm{TiO}_{2}$ material (denoted as SiTi) with an FSP setup, which has been described previously [25]. After synthesis, the SiTi was hydrogenated in a tube furnace (Carbolite, HST 12/400, $2000 \mathrm{~W}$, Hope Valley, UK) by heating to $500{ }^{\circ} \mathrm{C}$ at a rate of $5{ }^{\circ} \mathrm{C} / \mathrm{min}$ under a $50 \mathrm{~mL} / \mathrm{min}$ flow of $10 \% \mathrm{H}_{2}$ $\left(\mathrm{N}_{2}\right.$ balance). These conditions were maintained for $3 \mathrm{~h}$ before being cooled to ambient temperature. The hydrogenated samples are denoted as $\operatorname{SiTi}(\mathrm{H})$.

The plasma treatment was performed at ambient temperature in a dielectric barrier discharge (DBD) plasma reactor $(23 \mathrm{~W})$, consisting of a reaction kettle $(8 \mathrm{~mm}$ height, DBD-100, Corona Lab, Nanjing, China), discharge equipment (DBD-50), and a CPT-2000K plasma generator with a frequency range of 5-20 kHz. For each treatment, a 120-150 mg sample was spread over the middle of the reactor kettle. He (Coregas, >99.999\%) with a flowrate of $30 \mathrm{~mL} / \mathrm{min}$ was introduced into the reactor through insulated metal tubing and converted into a stable plasma upon entering the discharge area $(50 \mathrm{~mm}$ diameter). The net power used to generate the plasma was $15.0 \pm 0.1 \mathrm{~W}$. Plasma treatments of 5, 10, 20, and $30 \mathrm{~min}$ were used on the neat and hydrogenated SiTi samples, which are denoted as $\operatorname{SiTi}(x)$ or $\operatorname{SiTi}(\mathrm{H} x)$, respectively, where $x$ represents the plasma treatment time.

\subsection{Catalyst Characterization}

The catalyst specific surface area (SSA) was determined using a Micrometritics TriStar 3030 analyzer (Norcross, GA, USA) and calculated by the Brunauer-Emmett-Teller (BET) method. Samples were degassed at $150{ }^{\circ} \mathrm{C}$ for $3 \mathrm{~h}$ under vacuum prior to analysis. Sample crystallinity was determined by XRD analysis using a PANalytical Xpert multipurpose X-ray diffraction (MPD) instrument (Malvern, UK). The data was collected over an incident beam $\left(\mathrm{Cu} \mathrm{K}_{\alpha 1}\right)$ angle of $2 \theta$ from $10^{\circ}$ and $90^{\circ}$, with a step size of $0.026^{\circ}$.

UV-visible spectra were measured using a Shimadzu UV-3600 UV-vis NIR spectrophotometer (Columbia, MD, USA) with $\mathrm{BaSO}_{4}$ (Sigma-Aldrich, 99\%) as the reference. A light beam with a wavelength range of $200-800 \mathrm{~nm}$ was passed over the solid sample at a scan speed of $200 \mathrm{~nm}$ $\mathrm{min}^{-1}$. FTIR spectra were obtained using a PerkinElmer FTIR Spectrometer/Microscope (Waltham, MA, USA). The sample was exposed to infrared radiation with a wavenumber of 650 to $4000 \mathrm{~cm}^{-1}$ and 
the transmittance was recorded by PerkinElmer Spotlight 400 imaging system (Waltham, MA, USA), with a resolution of $4 \mathrm{~cm}^{-1}$.

Raman spectroscopy was carried out using a Renishaw inVia Raman microscope (Wotton-under-Edge, UK) in backscattering configuration, using an Ar laser to yield an excitation line of $514.5 \mathrm{~nm}$. Electron paramagnetic resonance (EPR) spectra of the samples were measured at the microwave frequency of $9.42 \mathrm{GHz}$ (X-band) and power of $2 \mathrm{~mW}$ in a Bruker EMX-plus X-band EPR spectrometer. The amplitude was modulated at $5 \mathrm{G}$ and the temperature set to $120 \mathrm{~K}$.

X-ray photoelectron spectroscopy (XPS) was conducted using a Thermo Scientific ESCALAB250Xi (Waltham, MA, USA). Monochromatic Al K $\alpha(1486.68 \mathrm{eV})$ radiation, with an emission power of $164 \mathrm{~W}$, was used as the source. The Ti2p, Si2p, and O1s core level spectra were recorded and referenced to the surface carbon C1s peak at $285 \mathrm{eV}$.

X-ray absorption spectroscopy (XAS) measurements were performed at the 10-BM beamline of the advanced photon source, Argonne national laboratory (Lemont, IL, USA). Prepared powders were loaded into $1 \mathrm{~mm}$ OD Kapton capillaries and measured in a transmission geometry. Anatase and rutile spectra were recorded using pure Sigma Aldrich and PC-50 (Millennium) nanoparticle samples, respectively. All data processing and analysis was performed using the Demeter XAS software package [26].

\subsection{Catalyst Activity Testing}

Photocatalytic formic acid oxidation was carried out in a reactor setup, as described previously [27], and comprised a glass spiral reactor that encircled a UV lamp (NEC, black light, $365 \mathrm{~nm}$ max emission, Minato, Japan). The catalyst mixture was prepared by adding $50 \mathrm{mg}$ of SiTi catalyst to $50 \mathrm{~mL}$ of Milli-Q water and sonicating for $15 \mathrm{~min}$ to ensure uniform dispersion within the suspension. Perchloric acid $(0.5 \mathrm{M})$ was added dropwise to the solution until a $\mathrm{pH}$ of $3.0 \pm 0.1$ was reached. The catalyst suspension was then added to the spiral reactor, where it was circulated using a peristaltic pump. The UV lamp was switched on for $30 \mathrm{~min}$ to eliminate organic matter in the mixture and ensure that the lamp intensity was constant. After switching the lamp off, the injection port was opened for $10 \mathrm{~min}$ to allow for equilibration with air, before closing the port once more for a further $10 \mathrm{~min}$. The formic acid oxidation reaction was commenced by switching on the lamp and adding $100 \mu \mathrm{mol}$ of formic acid. Mineralization of the acid was determined via a change in conductivity (as measured by a Jenway 3540 probe) as a result of carbon dioxide generation. Catalyst activity was compared according to the rate at which the catalyst achieved $50 \%$ conversion of the injected formic acid $\left(\mathrm{R}_{50}\right)$.

\section{Results and Discussion}

\subsection{Effect of Hydrogenation}

The $\mathrm{N}_{2}$ adsorption-desorption analyses of the neat and hydrogenated SiTi material reveals similar properties. Both samples display a similar type II isotherm and H3 hysteresis loop (Figure S1, Supporting Information). While this is often associated with macroporous materials, it has also been reported to result from mesopores forming between particle aggregates [28]. In the case of FSP-synthesized metal oxides, the formation of sinter bridges in the particle agglomerates affords this mesoporosity $[29,30]$. This is confirmed by the broad pore size distributions, displayed in Figure S2. SiTi and SiTi(H) display similar BET surface areas (98.7 and $96.4 \mathrm{~m}^{2} / \mathrm{g}$, respectively), suggesting that the hydrogenation treatment does not impact morphology or particle size.

A colour change from white to a pale blue was observed in the SiTi(H) sample after hydrogenation. This is attributed to the reduction of $\mathrm{Ti}^{4+}$ to $\mathrm{Ti}^{3+}[12,31]$, generating oxygen vacancies. The blue colour of $\operatorname{SiTi}(\mathrm{H})$ remained constant after hydrogenation, suggesting that the addition of $\mathrm{SiO}_{2}$ is able to effectively stabilise the $\mathrm{Ti}^{3+}$ site. The colour change in the material was further investigated with UV-vis analysis (Figure S3), where the emergence of a broad absorbance band was observed above $400 \mathrm{~nm}$ in $\mathrm{SiTi}(\mathrm{H})$. The band gap potential remained unchanged (approx. $3.40 \mathrm{eV}$ ) after hydrogenation, 
indicating that the presence of $\mathrm{SiO}_{2}$ enlarges the bang gap potential above pure anatase $(3.20 \mathrm{eV})$ and rutile $(3.02 \mathrm{eV}) \mathrm{TiO}_{2}$ [32], but is not affected by the hydrogenation process.

EPR was used to probe the $\mathrm{Si} / \mathrm{Ti}$ defects generated from hydrogenation, with the results shown in Figure 1. A sharp peak was observed at a g-value of 2.002 in the neat SiTi sample, which indicates that intrinsic E' centre defects [33] are present in the sample. These are suggested to form as a result of the flame spray pyrolysis synthesis [34]. As flame spray pyrolysis is a rapid process with a very high temperature gradient of cooling, perfect particle rearrangement is not achieved, and E' centres can be formed. Hydrogenation of the SiTi material did not affect the position of the E' centre peak, while an increase in peak amplitude for the $\mathrm{SiTi}(\mathrm{H})$ suggests that the process may lead to the formation of a greater number of $E^{\prime}$ centre defects. A broad peak at a g-value of 1.951 emerges in $\operatorname{SiTi}(\mathrm{H})$, with this peak position consistent with the formation of $\mathrm{Ti}^{3+}$ defects [19]. This is confirmation that the hydrogenation process is effective in partially reducing $\mathrm{Ti}^{4+}$ to $\mathrm{Ti}^{3+}$.

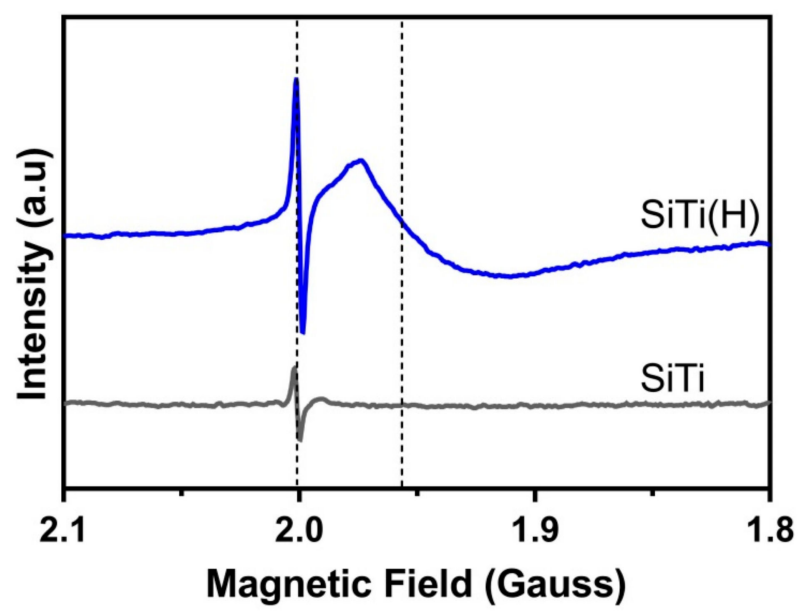

Figure 1. EPR spectra of the FSP-prepared SiTi before and after hydrogenation at $500{ }^{\circ} \mathrm{C}$. Spectra were acquired at $120 \mathrm{~K}$. Dotted lines indicate the presence of defects within the material.

The presence of $\mathrm{Ti}^{3+}$ defects after hydrogenation was confirmed in the Ti2p XPS spectra (Figure 2a), where the binding energy of the Ti2 $\mathrm{p}_{3 / 2}$ and Ti2 $\mathrm{p}_{1 / 2}$ peaks (observed at $459.2 \mathrm{eV}$ and $464.9 \mathrm{eV}$, respectively) remained constant, but two additional peaks at $458.3 \mathrm{eV}$ and $464.2 \mathrm{eV}$ are observed in SiTi(H). Analysis of the separate peaks in the Ti2p XPS spectra allowed for the quantity of $\mathrm{Ti}^{3+}$ in the SiTi material to be determined. While neat SiTi shows no sign of $\mathrm{Ti}^{3+}$ content being present, as confirmed by EPR and XPS analyses, hydrogenation resulted in a $3.9 \%$ content of $\mathrm{Ti}^{3+}$ in $\mathrm{SiTi}(\mathrm{H})$.

The Si2p spectra contains peaks at $103.5 \mathrm{eV}$ and $102.7 \mathrm{eV}$, which are attributed to $\mathrm{Si}^{4+} 2 \mathrm{p}_{1 / 2}$ and $\mathrm{Si}^{4+} 2 \mathrm{p}_{3 / 2}$, respectively. These peak positions are situated at a lower binding energy than what has been reported for $\mathrm{SiO}_{2}$ prepared via flame spray pyrolysis [35]. In this case, the shift of Si2p peak binding energy can be attributed to strong interactions between $\mathrm{Si}$ and Ti which are formed during synthesis. Hydrogenation of the SiTi material does not appear to affect this interaction, as the peak positions of $\mathrm{SiTi}(\mathrm{H})$ and SiTi are identical. This is confirmed in the O1s spectra, where the peak position of the O-Si $(530.5 \mathrm{eV})$ and $\mathrm{O}-\mathrm{Ti}(532.4 \mathrm{eV})$ are unchanged after hydrogenation.

Hydrogenation of the mixed SiTi material at $500{ }^{\circ} \mathrm{C}$ was an effective method of reducing $\mathrm{TiO}_{2}$ or $\mathrm{Ti}^{4+}$, as evidenced by the change in colour of $\operatorname{SiTi}(\mathrm{H})$ to blue and the accompanying broad absorbance above $400 \mathrm{~nm}$ in the UV-vis spectra. Furthermore, the generation of $\mathrm{Ti}^{3+}$ and accompanying oxygen vacancies is confirmed by the EPR and XPS analyses. Despite the change in Ti properties after hydrogenation, the crystallinity of the bulk material remains unchanged, as shown in Figure S4 (Supporting Information). This, combined with the unchanged relative surface area, shows that hydrogenation is an effective method of targeting changes in the $\mathrm{TiO}_{2}$ structure of the SiTi material. 

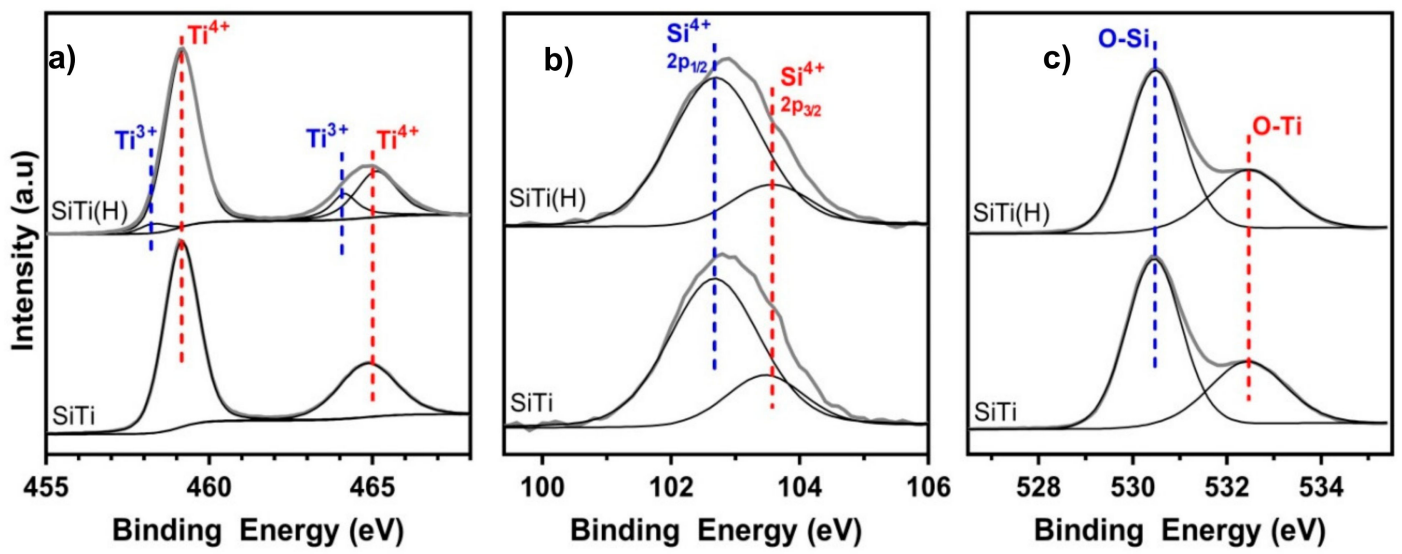

Figure 2. (a) Ti2p, (b) Si2p, and (c) O1s XPS spectra of the FSP-prepared SiTi materials before and after hydrogenation at $500{ }^{\circ} \mathrm{C}$.

\subsection{Effect of Plasma Treatment}

Plasma treatment offers a method of defect generation that is separate to hydrogenation. It is a low energy method, requiring only $27.6 \mathrm{~kJ}$ of energy over the course of the $20 \mathrm{~min}$ treatment. Thus, the impact of plasma treatment on the structure and performance of mixed $\mathrm{SiO}_{2} / \mathrm{TiO}_{2}$ materials before and after hydrogenation is assessed.

The X-Ray diffraction pattern (Figure S3) of both the neat SiTi and SiTi(H) sample displays a strong anatase crystal phase. A significantly weaker reflection for the rutile phase was also identified from the small peaks at $27.5^{\circ}, 36.1^{\circ}$, and $41.4^{\circ}$, which are characteristic of the (110), (101), and (111) planes. The anatase/rutile mixture is consistent with $\mathrm{TiO}_{2}$ synthesized via FSP [36]. After plasma treatment for $20 \mathrm{~min}$, no discernible change in peak position or amplitude was observed (as shown in Figure 3), regardless of whether the sample had previously been hydrogenated. This indicates that the anatase/rutile composition and crystallite size of the SiTi is left unchanged in the bulk sample. This does not rule out changes to the surface of the SiTi materials, as XRD does not have sufficient sensitivity to detect such changes, as shown by both Zhuang et al. [37] (for a He plasma system) and Kong et al. [20] (Ar plasma).

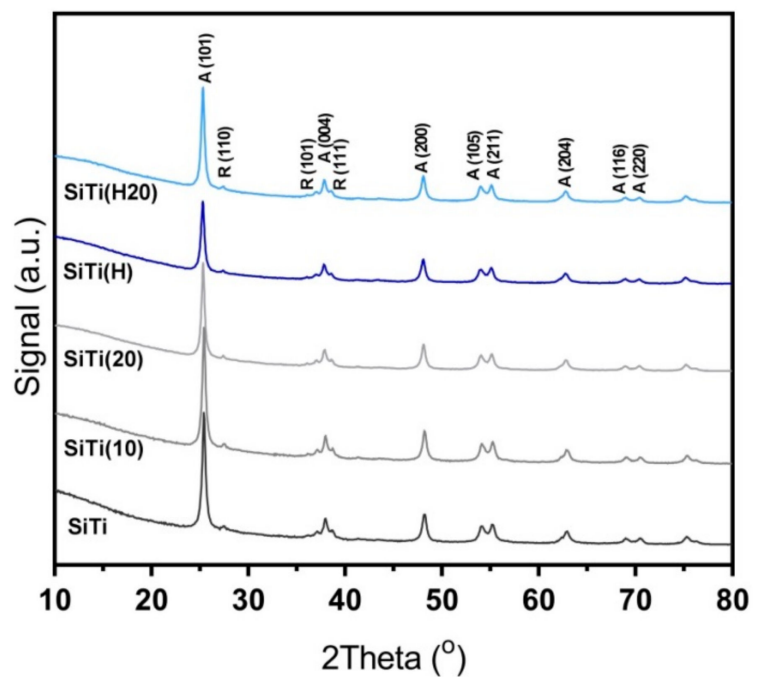

Figure 3. XRD reflections for FSP-synthesized SiTi after hydrogenation and/or plasma treatment.

Plasma treatment time denoted in brackets. Anatase (A) and Rutile (R) phases marked.

To further probe the impact of plasma treatment on the crystal microstructure of SiTi, Raman spectroscopy was carried out on $\mathrm{SiTi}$ and $\mathrm{SiTi}(\mathrm{H})$ after 0-20 min of plasma treatment (Figure 4). 
The peak locations in the Raman spectra are in agreement with anatase $\mathrm{TiO}_{2}[38,39]$. The sharp peak at a wavenumber of $144 \mathrm{~cm}^{-1}$, shoulder at $195 \mathrm{~cm}^{-1}$, and smaller peak at $638 \mathrm{~cm}^{-1}$ are attributed to $\mathrm{E}_{\mathrm{g}}$ symmetry. The peak at $397 \mathrm{~cm}^{-1}$ corresponds to the $B_{1 \mathrm{~g}}$ symmetry of anatase, while the peak at 515 $\mathrm{cm}^{-1}$ could represent the superposition of both the $A_{1 \mathrm{~g}}$ and $\mathrm{B}_{1 \mathrm{~g}}$ symmetry. Plasma treating the neat SiTi sample results in a slight broadening of the peaks and an increase in the ratio of the $B_{1 g}$ signal at $397 \mathrm{~cm}^{-1}$ to $E_{g}$ signal at $630 \mathrm{~cm}^{-1}$. This represents a decrease in local crystallinity as a result of prolonged plasma treatment. An additional peak emerges after 20 min of plasma treatment as a weak shoulder at approximately $440 \mathrm{~cm}^{-1}$. This peak position is similar to that reported for the $E_{\mathrm{g}}$ phase of rutile [40], but the lack of a corresponding $A_{1 g}$ peak at approximately $610 \mathrm{~cm}^{-1}$ suggests that there may be another explanation. For example, peak shift and broadening has also been observed for $\mathrm{TiO}_{2}$ materials when a surface oxygen deficiency is induced via reduction, where oxygen migrates from surface/subsurface of the $\mathrm{TiO}_{2}$ into the bulk [39]. Additionally, a shift or broadening of the $\mathrm{TiO}_{2}$ Raman spectra has also been reported when significant internal stress occurs [41]. This will be further explored with XPS analyses of the SiTi materials.
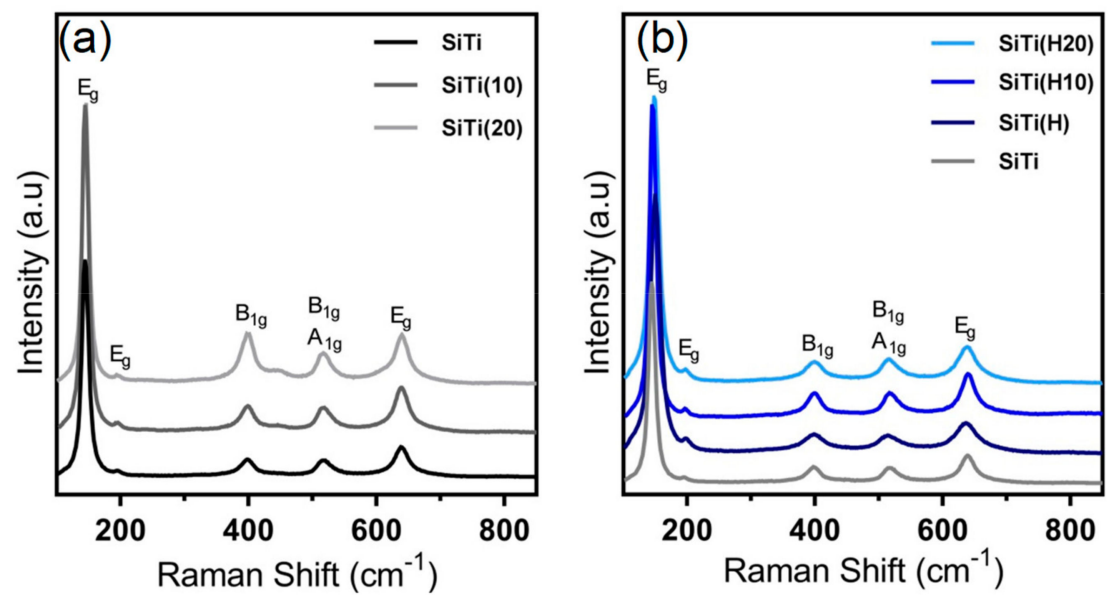

Figure 4. Raman spectra for FSP-synthesized SiTi, after the plasma treatment (with treatment time, in mins, in brackets) of (a) neat SiTi and (b) hydrogenated SiTi.

The effect of plasma treatment on $\mathrm{SiTi}(\mathrm{H})$ is less pronounced, as shown in Figure $4 \mathrm{~b}$. Hydrogenation results in slight peak broadening, potentially representing a decrease in crystallinity and structural symmetry as a result of the formation of $\mathrm{Ti}^{3+}$. A similar observation was made for SiTi(H20), but this trend was partially reversed for $\mathrm{SiTi}(\mathrm{H} 10)$, which was plasma treated for $10 \mathrm{~min}$. Unlike the neat SiTi, prolonged plasma treatment of the hydrogenated samples did not result in the emergence of a new peak. This suggests that the reduction of $\mathrm{Ti}^{4+}$ to $\mathrm{Ti}^{3+}$ via hydrogenation stabilises the $\mathrm{TiO}_{2}$ structure in $\operatorname{SiTi}(\mathrm{H})$.

Analysis of the surface of SiTi and SiTi(H) with XPS before and after plasma treatment revealed that even 10 min of plasma treatment is effective in generating $\mathrm{Ti}^{3+}$ defects, as shown in Figure $5 \mathrm{a}$. While the neat SiTi material contained only the $\mathrm{Ti}^{4+}$ species, SiTi(10) and SiTi(20) have a $\mathrm{Ti}^{3+}$ content of $5.5 \%$ and $6.5 \%$, respectively. Similarly, the plasma treatment increased the $\mathrm{Ti}^{3+}$ content of the hydrogenated $\mathrm{SiTi}(\mathrm{H})$ from $3.9 \%$ to $6.8 \%$ after a 20 min plasma treatment. Despite SiTi(10) and SiTi(20) being shown via XPS to contain significant $\mathrm{Ti}^{3+}$, no colour change to blue was observed. This is explained by the surface nature of the plasma treatment process and low penetration depth of XPS analyses [42]. Low temperature DBD plasma treatments have been shown to be effective in modifying the surface of materials [22,43], rather than the bulk, indicating that the $\mathrm{Ti}^{3+}$ content after plasma treatment is likely much higher on the surface of the SiTi materials than in the bulk. As a result, SiTi(10) and $\operatorname{SiTi}(20)$ remain white in colour. 

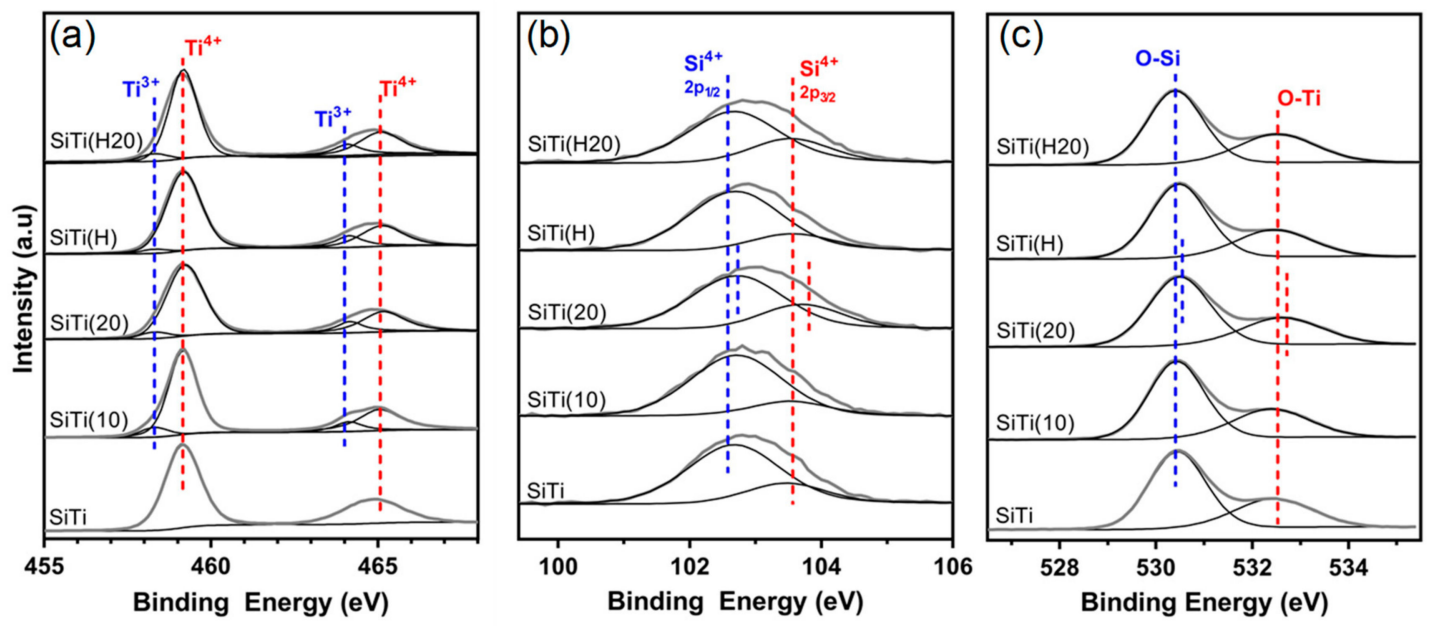

Figure 5. (a) Ti2p, (b) Si2p, and (c) O1s XPS spectra of the neat SiTi and hydrogenated SiTi(H) after plasma treatment for 10 and $20 \mathrm{~min}$.

The Si2p and O1s XPS spectra (Figure 5b,c, respectively) give an insight into the impact of the plasma treatment on the $\mathrm{O}$ and $\mathrm{Si}$ species in the SiTi materials. As already discussed, hydrogenation did not result in a shift in the binding energy of the peaks within the $\mathrm{Ti}$, $\mathrm{Si}$, or $\mathrm{O}$ spectra. Likewise, plasma treatment of SiTi for 10 min showed no significant peak shifts, however, increasing the treatment time to $20 \mathrm{~min}$ resulted in a peak shift of both the Si2p and O1s spectra for SiTi(20) to higher binding energy. This is evidence that the prolonged plasma treatment impacted the Si and O species near the catalyst surface. The shift to higher binding energy suggests that both $\mathrm{Si}$ and $\mathrm{O}$ have experienced a loss of electron density. This is the same sample which showed the emergence of an extra peak in the Raman spectra (Figure 4a), indicating that there may be a surface rearrangement which alters the way that $\mathrm{Si}$ and $\mathrm{O}$ interact on the catalyst surface. The shift of the Si2p spectra to higher BE represents a move towards pure $\mathrm{SiO}_{2}$ [44] and could signify a weakened interaction between the $\mathrm{Si}$ and $\mathrm{Ti}$ at the catalyst surface.

While plasma treatment of the hydrogenated $\operatorname{SiTi}(\mathrm{H})$ for 20 min resulted in an increase in $\mathrm{Ti}^{3+}$ content, it did not impact the Si2p or O1s spectra, where no peak shifts can be observed. This supports the observations from Raman spectroscopy (Figure $4 \mathrm{~b}$ ) and is further evidence that hydrogenation goes some way toward stabilising the $\mathrm{Si}-\mathrm{Ti}$ interaction at the catalyst surface against plasma treatment, relative to the neat SiTi material.

Ti K-edge XAS experiments were used to further understand the structural and chemical effects of hydrogenation and plasma processing on the SiTi. The X-ray absorption near edge spectra (XANES) for plasma treated and hydrogenated samples are shown in Figure 6 and are sensitive to local electronic structure, oxidation state, and local Ti-symmetry. The pre-edge feature of the Ti K-edge, representing 1 $\mathrm{s} \rightarrow 3 \mathrm{~d}$ electronic transitions, is particularly sensitive to changes in local Ti symmetry and showcases notable structural changes across all samples. For reference, anatase and rutile are used for comparison purposes, along with SiTi and $\mathrm{TiO}_{2}$ synthesized via $\mathrm{FSP}$ without further chemical modification. Anatase exhibits well characterized pre-edge features at $4969 \mathrm{eV}, 4972 \mathrm{eV}$, and $4974 \mathrm{eV}$, while rutile pre-edge features are positioned at $4971 \mathrm{eV}$ and $4974 \mathrm{eV}$, with a small shoulder peak at $4969 \mathrm{eV}$. The materials synthesized by FSP exhibit very similar pre-edge features to anatase, suggesting the $\mathrm{Ti}$ atoms hold an anatase-type symmetry that is minimally influenced by the $\mathrm{Si}$ atoms, confirming the XRD and Raman analyses. Similarly, pre-edge feature positions for each hydrogenated SiTi material align with anatase, suggesting hydrogenation does not drastically alter the local Ti symmetry. 

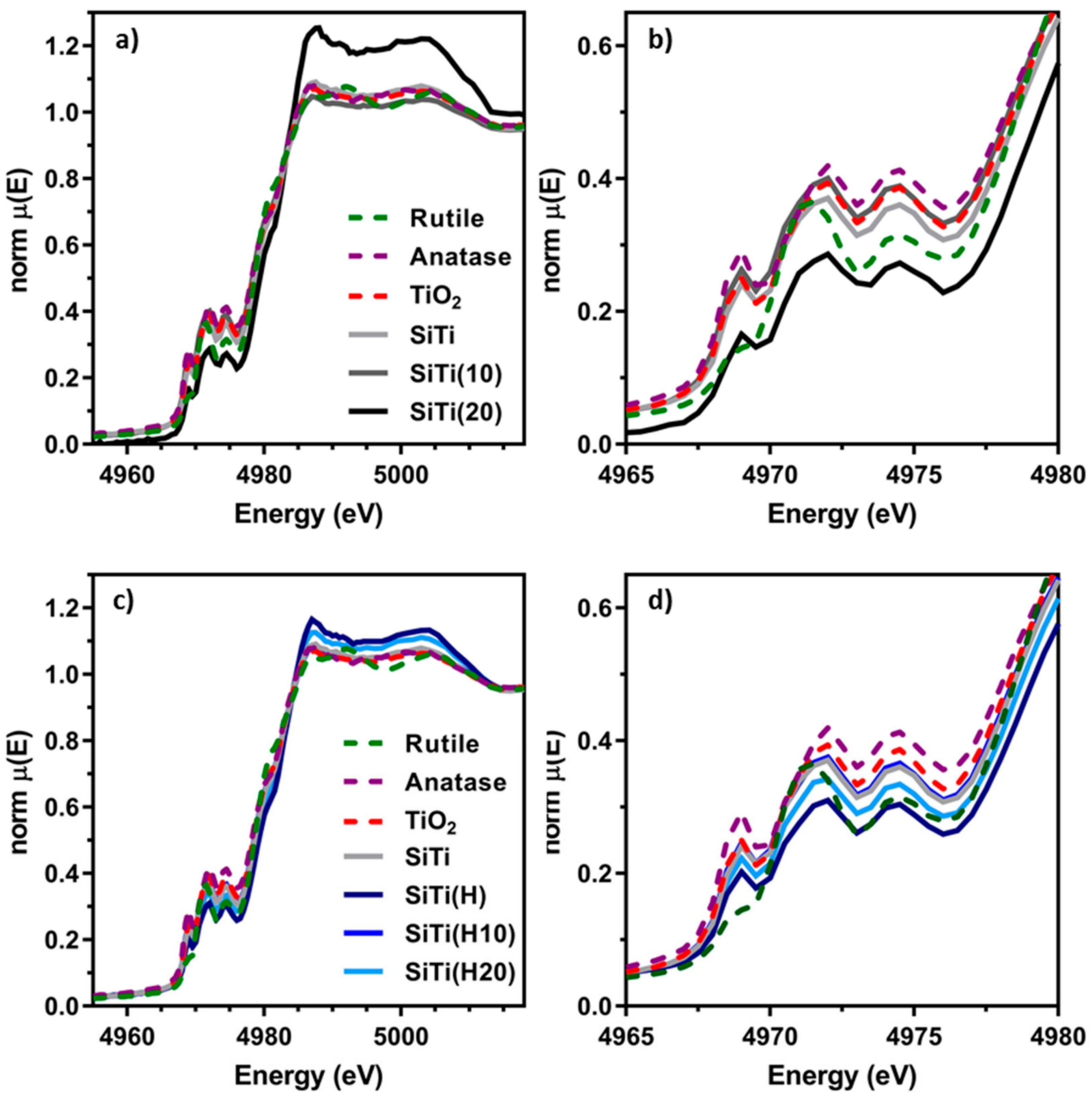

Figure 6. (a) Ti-K edge and (b) pre-edge XANES for FSP-synthesized SiTi before and after 10 and 20 min of plasma treatment. (c) Ti-K edge and (d) pre-edge XANES for FSP-synthesized SiTi after hydrogenation and/or 10-20 min of plasma treatment. Pure anatase, rutile, and FSP-prepared $\mathrm{TiO}_{2}$ controls are also included.

Unlike the hydrogenated samples, plasma treatment of the neat SiTi exhibits notable structural differences. SiTi(10) exhibits pre-edge features similar to anatase coupled with an additional shoulder at $4970 \mathrm{eV}$. The shoulder is likely indicative of the formation of five-fold coordinated Ti [45] rather than the formation of rutile, given that the lowest edge pre-edge feature is still present. The pre-edge features of SiTi(20) exhibit further perturbations away from the parent materials, where the lowest energy pre-edge feature is more similar to that of rutile, coupled with relative peak intensity changes. Examination of the pre-edge feature overall showcases that plasma treatment of SiTi materials influences the local symmetry of $\mathrm{Ti}$, with longer plasma treatment times leading to more pronounced changes in material structure. This is expected to influence the catalytic properties of these materials.

Further examination of the XANES showcases additional changes in chemical and electronic structure of the SiTi materials with hydrogenation and plasma treatment. Overall, the shape of the XANES is very similar to that of anatase for all SiTi, consistent with our analysis of the pre-edge features above. Modest white line intensity increases are observed for the SiTi(H) and $\mathrm{SiTi}(\mathrm{H} 20)$ materials, while a much larger white line intensity is observed for SiTi(20). Increases in white line intensity indicate that the excited electron can access higher order molecular orbitals in the conduction band, almost always due to local electronic withdrawing effects of nearby atoms and/or a change in oxidation state. SiTi(20) also exhibits a large shift in $\mathrm{E}_{0}$ to higher energy, suggesting a bulk increase in Ti oxidation 
state. This is in line with the Raman analysis of SiTi(20), where peak broadening was attributed to a potential migration of surface or sub-surface oxygen into the bulk $\mathrm{TiO}_{2}$ material.

The extended X-ray absorption fine structure (EXAFS) spectra, presented in Figure 7, provides location structural information of the Ti-O and Ti-Ti nearest neighbour distances (NNDs). Note that all distances are not corrected for phase shift and are $\sim 0.4 \AA$ shorter than the actual NNDs. Both anatase and rutile exhibit at Ti-O NND $1.56 \AA$. Unmodified $\mathrm{TiO}_{2}$ synthesized by FSP exhibits a similar Ti-O NND, while the SiTi material has a reduced NND of $1.50 \AA$. For the hydrogenated materials, the Ti-O NNDs are 1.50, 1.55, and $1.52 \AA$ for $\operatorname{SiTi}(\mathrm{H}), \mathrm{SiTi}(\mathrm{H} 10)$, and SiTi(H20), respectively. Note that these NNDs fall between the unmodified SiTi material and pure anatase, strongly suggesting that hydrogenation is affecting the local structure of the material. For the plasma treated materials, SiTi(10) exhibits a Ti-O NND of $1.51 \AA$, while a NND of $1.43 \AA$ is observed for the SiTi(20). This large contraction of the Ti-O NND indicates that plasma treatment is having a profound effect on the structure of the catalysts, which in turn influences the catalytic properties.

Plasma induced structural changes are even more severely apparent when comparing longer NNDs corresponding to Ti-Ti distances of $2.32 \AA$ and $3.12 \AA$ in anatase. The starting SiTi FSP material exhibits significantly reduced features at these distances, which is expected when considering the nanoscale size of the particles. Upon plasma treatment, the Ti-Ti NNDs shift in the SiTi(10) sample, while a new feature appears in the SiTi(20) material. This feature has a maximum at $2.51 \AA$ and a shoulder at $2.87 \AA$, which corresponds to an expansion and contraction of the relative Ti-Ti distance in anatase. The origin of these features cannot be determined at this time but must be due to a structural rearrangement of local Ti clusters due to the increased number of defects present in the material as a result of the prolonged plasma treatment. For the hydrothermally treated materials, the shift to longer NNDs is notable for all materials, indicative of a possible lattice expansion, although all samples retain the profile of an anatase-type structure. This suggests that the extended plasma treatment time for the SiTi material after hydrogenation has a less pronounced effect on Ti bonding, supporting the suggestion that hydrogenation assists in stabilising the $\mathrm{TiO}_{2}$ structure.
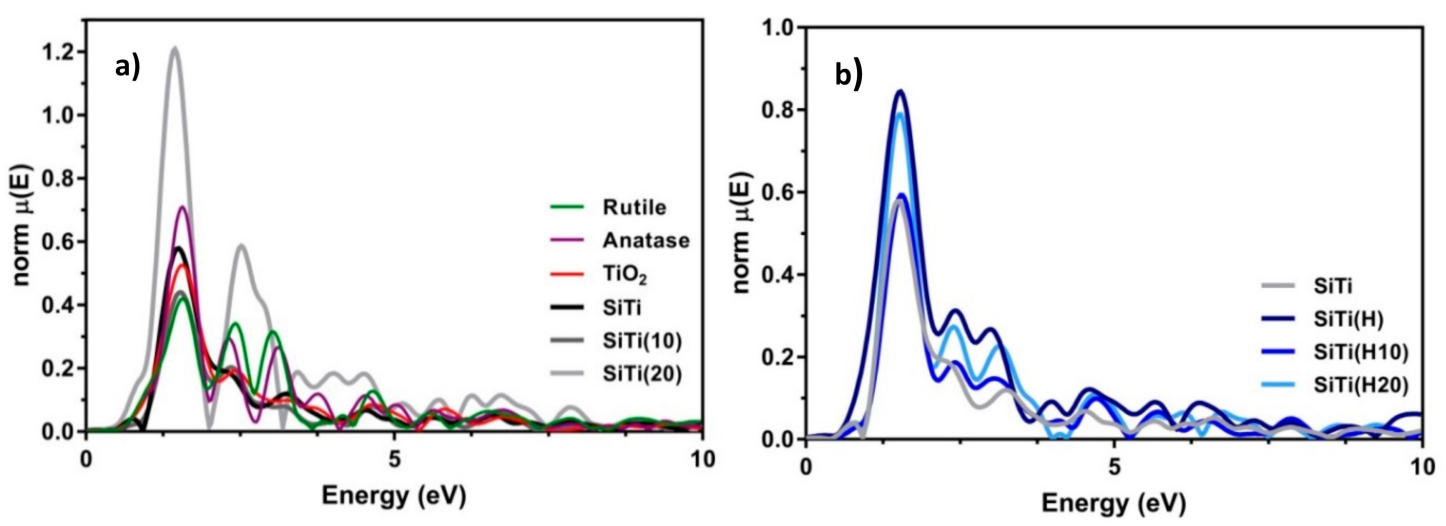

Figure 7. Ti K-edge EXAFS spectra of FSP-synthesized SiTi (a) before and (b) after hydrogenation and plasma treatment. Pure anatase, rutile, and FSP-prepared $\mathrm{TiO}_{2}$ controls are also included.

Plasma treatment of the mixed $\mathrm{SiO}_{2} / \mathrm{TiO}_{2}$ material before and after hydrogenation invokes modifications in the material structure and properties. The surface area and crystallinity of the SiTi materials is unaffected by up to 20 min of plasma treatment. Both the SiTi and SiTi $(\mathrm{H})$ materials are altered by plasma treatment, according to the XPS analyses, with the reduction of $\mathrm{Ti}^{4+}$ to $\mathrm{Ti}^{3+}$ occurring among all samples, although the change brought about by plasma treatment was confined to the catalyst surface. XAS analyses demonstrate that chemical/structural changes occur in the SiTi materials, with more pronounced changes observed in the materials which did not undergo hydrogenation. In particular, there is an increase in the oxidation state (from XANES) and the emergence of new Ti-Ti features in SiTi(20). This same material exhibits a peak shift and broadening in Raman spectroscopy and 
a peak shift in the Si2p and O1s XPS spectra, which represents a change in the surface Si and O species, which may be related to a significant surface oxygen deficiency or internal stress. Hydrogenating the catalyst prior to conducting plasma treatment appears to be an effective way to limit these changes.

\subsection{Photocatalytic Formic Acid Oxidation}

The ability of the mixed SiTi catalysts to activate oxygen was examined by monitoring the oxidation of formic acid under UV illumination. The mineralization of carbon and the rate of $50 \%$ formic acid oxidation $\left(\mathrm{R}_{50}\right)$ were determined (Figure 8). Neat SiTi achieved a low rate of carbon mineralization, with only approximately $60 \%$ of the initial $100 \mu \mathrm{mol}$ of formic acid oxidised to carbon dioxide after $30 \mathrm{~min}$. As a result, the $\mathrm{R}_{50}$ of SiTi is $1.79 \mu \mathrm{mol} / \mathrm{min}$. A $10 \mathrm{~min}$ plasma treatment of SiTi resulted in a sharp increase in the rate of carbon mineralization, especially in the first $10 \mathrm{~min}$ of activity, with SiTi(10) presenting an $R_{50}$ of $3.16 \mu \mathrm{mol} / \mathrm{min}$. This increase in the $\mathrm{R}_{50}$ can be attributed to the generation of surface $\mathrm{Ti}^{3+}$ species during plasma treatment. XPS revealed that the plasma treatment is effective in increasing the number of surface $\mathrm{Ti}^{3+}$ species, which likely contributes to the increase in activity for $\mathrm{SiTi}(10)$ relative to $\mathrm{SiTi}$, as the $\mathrm{Ti}^{3+}$ was identified in a previous study as an active site for formic acid oxidation [19]. Furthermore, studies investigating the photocatalytic activity of doped $\mathrm{TiO}_{2}$ materials have shown that, while $\mathrm{Ti}^{3+}$ is a key component in oxygen activation, it is stable and remains active across multiple reaction cycles [46,47].
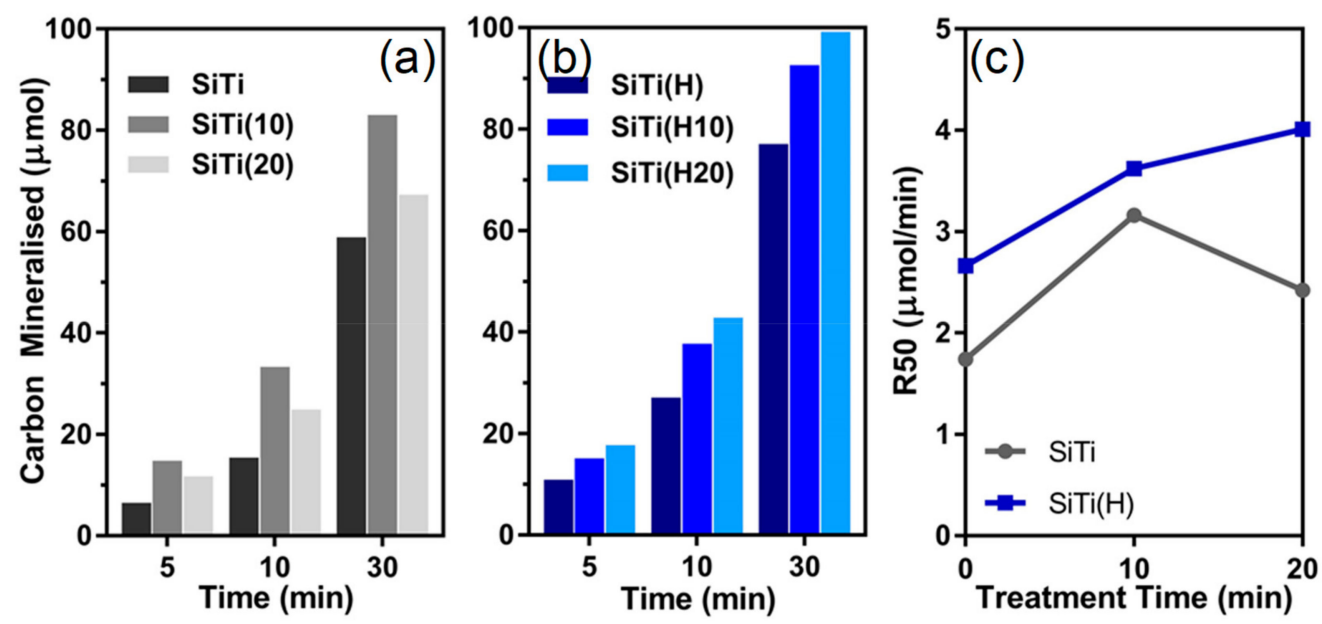

Figure 8. Carbon mineralization of (a) neat SiTi after plasma treatment, (b) hydrogenated SiTi after plasma treatment, and $(c)$ the rate of photocatalytic formic acid oxidation $\left(R_{50}\right)$. Catalyst loading $=1 \mathrm{~g} / \mathrm{mL}$; suspension volume $=50 \mathrm{~mL}$; suspension $\mathrm{pH}=3 \pm 0.1$; formic acid loading $=100 \mu \mathrm{mol}$.

Increasing the plasma treatment to $20 \mathrm{~min}$ for $\mathrm{SiTi}(20)$ then caused a drop in performance, with the $\mathrm{R}_{50}$ of $2.42 \mu \mathrm{mol} / \mathrm{min}$. The changes in material properties offer an explanation for this decrease in activity between 10 and $20 \mathrm{~min}$ of plasma treatment. While the plasma treatment did not affect the bulk $\mathrm{TiO}_{2}$ material, it resulted in significant changes to the catalyst surface. SiTi(20) was found with Raman and XPS to exhibit oxygen deficiencies and a decreased electron density for surface Si and O species. Thus, even though the surface $\mathrm{Ti}^{3+}$ content on $\operatorname{SiTi}(20)(6.5 \%)$ was higher than $\operatorname{SiTi}(10)(5.5 \%)$, the weakened interaction between $\mathrm{Si} / \mathrm{O}$ and $\mathrm{Ti}$ at the catalyst surface outweighed this and decreased the photocatalytic activity of $\mathrm{SiTi}(20)$.

Hydrogenation of the mixed $\mathrm{SiO}_{2} / \mathrm{TiO}_{2}$ material increased its photocatalytic activity, where $\mathrm{SiTi}(\mathrm{H})$ achieves an $\mathrm{R}_{50}$ of $2.66 \mu \mathrm{mol} / \mathrm{min}$ compared to $1.79 \mu \mathrm{mol} / \mathrm{min}$ for neat SiTi. This increase in the rate of formic acid oxidation can be attributed to the reduction of $\mathrm{Ti}^{4+}$ to $\mathrm{Ti}^{3+}$ during the hydrogenation process. Plasma treatment of the hydrogenated sample resulted in a further increase in the rate of formic acid oxidation, with SiTi(H10) and SiTi(H20) achieving 92 and 99\% conversion of formic acid in $30 \mathrm{~min}$, respectively, corresponding to $\mathrm{R}_{50}$ values of 3.62 and $4.01 \mu \mathrm{mol} / \mathrm{min}$. This improvement can 
be attributed to the greater $\mathrm{Ti}^{3+}$ presence on the surface of $\mathrm{SiTi}(\mathrm{H} 10)$ and $\mathrm{SiTi}(\mathrm{H} 20)$ and the stabilization of the SiTi material as a result of hydrogenation. As a result, the plasma treatment of the hydrogenated $\mathrm{SiO}_{2} / \mathrm{TiO}_{2}$ material results in further reduction of $\mathrm{Ti}^{4+}$ species present at or near the catalyst surface without impacting the $\mathrm{Si}-\mathrm{Ti}$ interaction.

\section{Conclusions}

Mixed $\mathrm{SiO}_{2} / \mathrm{TiO}_{2}$ materials, synthesized via flame spray pyrolysis, were investigated as catalysts for the photocatalytic oxidation of formic acid. Hydrogenation of the SiTi materials was shown with EPR and XPS to result in the bulk reduction of $\mathrm{Ti}^{4+}$ to $\mathrm{Ti}^{3+}$. Plasma treatment of both the neat and hydrogenated SiTi materials resulted in the formation of increasing $\mathrm{Ti}^{3+}$ species at the catalyst surface, while the bulk material was left unaffected. The catalytic activity of the materials after hydrogenation and/or plasma treatment increased by approximately 40 to $130 \%$, confirming that $\mathrm{Ti}^{3+}$ is integral in driving oxygen activation reactions. While higher $\mathrm{Ti}^{3+}$ content was related to increase photocatalytic activity, plasma treatment of the neat SiTi for $20 \mathrm{~min}$ was shown to result in a decreased $\mathrm{Si}-\mathrm{Ti}$ interaction, which led to a drop in the rate of formic acid oxidation. This approach of introducing material defects presents a promising method for improving the performance of noble metal-free catalysts for oxygen activation reactions and could potentially be applied to advanced oxidation processes such as catalytic ozonation.

Supplementary Materials: The following are available online at http://www.mdpi.com/1996-1944/12/17/2756/s1, Figure S1: Nitrogen adsorption-desorption isotherms of FSP-prepared SiTi before and after hydrogenation, Figure S2: Pore size distributions of FSP-prepared SiTi before and after hydrogenation, Figure S3: UV-Visible spectra of FSP-prepared SiTi before and after hydrogenation, measured using a $\mathrm{BaSO}_{4}$ reference, Figure S4: XRD reflections for FSP-synthesised SiTi before and after hydrogenation. Anatase (A) and Rutile (R) phases marked.

Author Contributions: Conceptualization, J.S., J.H., and R.A.; formal analysis, J.H., A.N., E.L., R.D., N.B., and Y.W.; investigation, J.H., E.L., R.D., A.N., N.B. and Y.W..; writing- original draft preparation, A.N. and J.H.; writing — review and editing, J.H., E.L., J.S., N.B. and R.A.; supervision, J.S., R.A.

Funding: This research was funded by Australian Research Council under the Laureate Fellowship Scheme (FL140100081).

Acknowledgments: This research used the 10-BM of the Advanced Photon Source, a U.S. Department of Energy (DOE) Office of Science User Facility operated for the DOE Office of Science by Argonne National Laboratory under Contract No. DE-AC02-06CH11357. Operations of 10-BM are further supported by the Materials Research Collaborative Access Team (MRCAT) by the Department of Energy and the MRCAT member institutions. We would thank Yujia Ding for assistance with experiments at 10-BM.

Conflicts of Interest: The authors declare no conflict of interest. The funders had no role in the design of the study; in the collection, analyses, or interpretation of data; in the writing of the manuscript, or in the decision to publish the results.

\section{References}

1. Bion, N.; Epron, F.; Moreno, M.; Mariño, F.; Duprez, D. Preferential Oxidation of Carbon Monoxide in the Presence of Hydrogen (PROX) over Noble Metals and Transition Metal Oxides: Advantages and Drawbacks. Top. Catal. 2008, 51, 76. [CrossRef]

2. Lawrence, N.J;; Brewer, J.R.; Wang, L.; Wu, T.-S.; Wells-Kingsbury, J.; Ihrig, M.M.; Wang, G.; Soo, Y.-L.; Mei, W.-N.; Cheung, C.L. Defect Engineering in Cubic Cerium Oxide Nanostructures for Catalytic Oxidation. Nano Lett. 2011, 11, 2666-2671. [CrossRef] [PubMed]

3. Li, Y.; Wei, Z.; Gao, F.; Kovarik, L.; Baylon, R.A.L.; Peden, C.H.F.; Wang, Y. Effect of Oxygen Defects on the Catalytic Performance of $\mathrm{VO}_{\mathrm{x}} / \mathrm{CeO}_{2}$ Catalysts for Oxidative Dehydrogenation of Methanol. ACS Catal. 2015, 5, 3006-3012. [CrossRef]

4. Kandiel, T.A.; Ahmed, A.Y.; Bahnemann, D. $\mathrm{TiO}_{2}$ (B)/anatase heterostructure nanofibers decorated with anatase nanoparticles as efficient photocatalysts for methanol oxidation. J. Mol. Catal. A Chem. 2016, 425, 55-60. [CrossRef] 
5. Sihaib, Z.; Puleo, F.; Garcia-Vargas, J.M.; Retailleau, L.; Descorme, C.; Liotta, L.F.; Valverde, J.L.; Gil, S.; Giroir-Fendler, A. Manganese oxide-based catalysts for toluene oxidation. Appl. Catal. B Environ. 2017, 209, 689-700. [CrossRef]

6. Carabineiro, S.A.C.; Chen, X.; Konsolakis, M.; Psarras, A.C.; Tavares, P.B.; Órfão, J.J.M.; Pereira, M.F.R.; Figueiredo, J.L. Catalytic oxidation of toluene on Ce-Co and La-Co mixed oxides synthesized by exotemplating and evaporation methods. Catal. Today 2015, 244, 161-171. [CrossRef]

7. Quiroz, J.; Giraudon, J.-M.; Gervasini, A.; Dujardin, C.; Lancelot, C.; Trentesaux, M.; Lamonier, J.-F. Total Oxidation of Formaldehyde over $\mathrm{MnO}_{\mathrm{x}}-\mathrm{CeO}_{2}$ Catalysts: The Effect of Acid Treatment. ACS Catal. 2015, 5, 2260-2269. [CrossRef]

8. Zhang, G.; Sun, Z.; Duan, Y.; Ma, R.; Zheng, S. Synthesis of nano- $\mathrm{TiO}_{2} /$ diatomite composite and its photocatalytic degradation of gaseous formaldehyde. Appl. Surf. Sci. 2017, 412, 105-112. [CrossRef]

9. Wang, G.; Yang, Y.; Han, D.; Li, Y. Oxygen defective metal oxides for energy conversion and storage. Nano Today 2017, 13, 23-39. [CrossRef]

10. Zhu, Y.; Zhou, W.; Yu, J.; Chen, Y.; Liu, M.; Shao, Z. Enhancing Electrocatalytic Activity of Perovskite Oxides by Tuning Cation Deficiency for Oxygen Reduction and Evolution Reactions. Chem. Mater. 2016, 28, 1691-1697. [CrossRef]

11. Jia, J.; Qian, C.; Dong, Y.; Li, Y.F.; Wang, H.; Ghoussoub, M.; Butler, K.T.; Walsh, A.; Ozin, G.A. Heterogeneous catalytic hydrogenation of $\mathrm{CO}_{2}$ by metal oxides: Defect engineering-perfecting imperfection. Chem. Soc. Rev. 2017, 46, 4631-4644. [CrossRef]

12. Saputera, W.H.; Mul, G.; Hamdy, M.S. Ti ${ }^{3+}$-containing titania: Synthesis tactics and photocatalytic performance. Catal. Today 2015, 246, 60-66. [CrossRef]

13. Li, Y.; Wang, W.; Wang, F.; Di, L.; Yang, S.; Zhu, S.; Yao, Y.; Ma, C.; Dai, B.; Yu, F. Enhanced Photocatalytic Degradation of Organic Dyes via Defect-Rich $\mathrm{TiO}_{2}$ Prepared by Dielectric Barrier Discharge Plasma. Nanomaterials 2019, 9, 720. [CrossRef]

14. Gao, L.; Li, Y.; Ren, J.; Wang, S.; Wang, R.; Fu, G.; Hu, Y. Passivation of defect states in anatase $\mathrm{TiO}_{2}$ hollow spheres with Mg doping: Realizing efficient photocatalytic overall water splitting. Appl. Catal. B Environ. 2017, 202, 127-133. [CrossRef]

15. Saputera, W.H.; Tahini, H.A.; Lovell, E.C.; Tan, T.H.; Rawal, A.; Aguey-Zinsou, K.-F.; Friedmann, D.; Smith, S.C.; Amal, R.; Scott, J. Cooperative defect-enriched $\mathrm{SiO}_{2}$ for oxygen activation and organic dehydrogenation. J. Catal. 2019, 376, 168-179. [CrossRef]

16. Fujishima, A.; Zhang, X.; Tryk, D.A. $\mathrm{TiO}_{2}$ photocatalysis and related surface phenomena. Surf. Sci. Rep. 2008, 63, 515-582. [CrossRef]

17. Yoshihara, T.; Katoh, R.; Furube, A.; Tamaki, Y.; Murai, M.; Hara, K.; Murata, S.; Arakawa, H.; Tachiya, M. Identification of Reactive Species in Photoexcited Nanocrystalline $\mathrm{TiO}_{2}$ Films by Wide-Wavelength-Range (400-2500 nm) Transient Absorption Spectroscopy. J. Phys. Chem. B 2004, 108, 3817-3823. [CrossRef]

18. Chen, X.; Liu, L.; Peter, Y.Y.; Mao, S.S. Increasing solar absorption for photocatalysis with black hydrogenated titanium dioxide nanocrystals. Science 2011, 331, 746-750. [CrossRef]

19. Saputera, W.H.; Tahini,H.A.; Sabsabi, M.; Tan, T.H.; Bedford, N.M.; Lovell, E.; Cui, Y.; Hart, J.N.; Friedmann, D.; Smith, S.C.; et al. Light-Induced Synergistic Multidefect Sites on $\mathrm{TiO}_{2} / \mathrm{SiO}_{2}$ Composites for Catalytic Dehydrogenation. ACS Catal. 2019, 9, 2674-2684. [CrossRef]

20. Kong, X.; Xu, Y.; Cui, Z.; Li, Z.; Liang, Y.; Gao, Z.; Zhu, S.; Yang, X. Defect enhances photocatalytic activity of ultrathin $\mathrm{TiO}_{2}(\mathrm{~B})$ nanosheets for hydrogen production by plasma engraving method. Appl. Catal. B Environ. 2018, 230, 11-17. [CrossRef]

21. Neyts, E.C.; Ostrikov, K.; Sunkara, M.K.; Bogaerts, A. Plasma Catalysis: Synergistic Effects at the Nanoscale. Chem. Rev. 2015, 115, 13408-13446. [CrossRef]

22. Li, B.; Zhao, Z.; Zhou, Q.; Meng, B.; Meng, X.; Qiu, J. Highly Efficient Low-Temperature Plasma-Assisted Modification of $\mathrm{TiO}_{2}$ Nanosheets with Exposed $\{001\}$ Facets for Enhanced Visible-Light Photocatalytic Activity. Chem. A Eur. J. 2014, 20, 14763-14770. [CrossRef]

23. Wang, N.; Shen, K.; Huang, L.; Yu, X.; Qian, W.; Chu, W. Facile Route for Synthesizing Ordered Mesoporous $\mathrm{Ni}-\mathrm{Ce}-\mathrm{Al}$ Oxide Materials and Their Catalytic Performance for Methane Dry Reforming to Hydrogen and Syngas. ACS Catal. 2013, 3, 1638-1651. [CrossRef] 
24. Jedsukontorn, T.; Ueno, T.; Saito, N.; Hunsom, M. Narrowing band gap energy of defective black $\mathrm{TiO}_{2}$ fabricated by solution plasma process and its photocatalytic activity on glycerol transformation. J. Alloys Compd. 2018, 757, 188-199. [CrossRef]

25. Horlyck, J.; Sara, M.; Lovell, E.C.; Amal, R.; Scott, J.A. Effect of metal-support interactions in mixed Co/Al catalysts for dry reforming of methane. Chem CatChem 2019, 11, 3432. [CrossRef]

26. Ravel, B.; Newville, M. ATHENA, ARTEMIS, HEPHAESTUS: Data analysis for $x$-ray absorption spectroscopy using IFEFFIT. J. Synchrotron Radiat. 2005, 12, 537-541. [CrossRef]

27. Abdullah, M.; Low, G.K.C.; Matthews, R.W. Effects of common inorganic anions on rates of photocatalytic oxidation of organic carbon over illuminated titanium dioxide. J. Phys. Chem. 1990, 94, 6820-6825. [CrossRef]

28. Kruk, M.; Jaroniec, M. Gas adsorption characterization of ordered organic-inorganic nanocomposite materials. Chem. Mater. 2001, 13, 3169-3183. [CrossRef]

29. Tok, A.I.Y.; Boey, F.Y.C.; Du, S.W.; Wong, B.K. Flame spray synthesis of $\mathrm{ZrO}_{2}$ nano-particles using liquid precursors. Mater. Sci. Eng. B 2006, 130, 114-119. [CrossRef]

30. Teoh, W.Y.; Amal, R.; Mädler, L. Flame spray pyrolysis: An enabling technology for nanoparticles design and fabrication. Nanoscale 2010, 2, 1324-1347. [CrossRef]

31. Yin, G.; Huang, X.; Chen, T.; Zhao, W.; Bi, Q.; Xu, J.; Han, Y.; Huang, F. Hydrogenated Blue Titania for Efficient Solar to Chemical Conversions: Preparation, Characterization, and Reaction Mechanism of $\mathrm{CO}_{2}$ Reduction. ACS Catal. 2018, 8, 1009-1017. [CrossRef]

32. Scanlon, D.O.; Dunnill, C.W.; Buckeridge, J.; Shevlin, S.A.; Logsdail, A.J.; Woodley, S.M.; Catlow, C.R.A.; Powell, M.J.; Palgrave, R.G.; Parkin, I.P. Band alignment of rutile and anatase $\mathrm{TiO}_{2}$. Nat. Mater. 2013, $12,798$. [CrossRef]

33. Howe, R.F.; Gratzel, M. EPR observation of trapped electrons in colloidal titanium dioxide. J. Phys. Chem. 1985, 89, 4495-4499. [CrossRef]

34. Emeline, A.V.; Sheremetyeva, N.V.; Khomchenko, N.V.; Kuzmin, G.N.; Ryabchuk, V.K.; Teoh, W.Y.; Amal, R. Spectroscopic Studies of Pristine and Fluorinated $\mathrm{Nano}-\mathrm{ZrO}_{2}$ in Photostimulated Heterogeneous Processes. J. Phys. Chem. C 2009, 113, 4566-4574. [CrossRef]

35. Kho, E.T.; Lovell, E.; Wong, R.J.; Scott, J.; Amal, R. Manipulating ceria-titania binary oxide features and their impact as nickel catalyst supports for low temperature steam reforming of methane. Appl. Catal. A Gen. 2017, 530, 111-124. [CrossRef]

36. Chiarello, G.L.; Selli, E.; Forni, L. Photocatalytic hydrogen production over flame spray pyrolysis-synthesised $\mathrm{TiO}_{2}$ and $\mathrm{Au} / \mathrm{TiO}_{2}$. Appl. Catal. B Environ. 2008, 84, 332-339. [CrossRef]

37. Zhuang, J.; Dai, W.; Tian, Q.; Li, Z.; Xie, L.; Wang, J.; Liu, P.; Shi, X.; Wang, D. Photocatalytic degradation of $\mathrm{RhB}$ over $\mathrm{TiO}_{2}$ bilayer films: Effect of defects and their location. Langmuir 2010, 26, 9686-9694. [CrossRef]

38. Ohsaka, T.; Izumi, F.; Fujiki, Y. Raman spectrum of anatase, $\mathrm{TiO}_{2}$. J. Raman Spectrosc. 1978, 7, $321-324$. [CrossRef]

39. Parker, J.C.; Siegel, R.W. Raman microprobe study of nanophase $\mathrm{TiO}_{2}$ and oxidation-induced spectral changes. J. Mater. Res. 1990, 5, 1246-1252. [CrossRef]

40. Lan, T.; Tang, X.; Fultz, B. Phonon anharmonicity of rutile $\mathrm{TiO}_{2}$ studied by Raman spectrometry and molecular dynamics simulations. Phys. Rev. B Condens. Matter Mater. Phys. 2012, 85, 1-11. [CrossRef]

41. Oh, S.-M.; Ishigaki, T. Preparation of pure rutile and anatase $\mathrm{TiO}_{2}$ nanopowders using $\mathrm{RF}$ thermal plasma. Thin Solid Films 2004, 457, 186-191. [CrossRef]

42. Watts, J.F. X-ray photoelectron spectroscopy. Vacuum 1994, 45, 653-671. [CrossRef]

43. Boutonnet Kizling, M.; Järås, S.G. A review of the use of plasma techniques in catalyst preparation and catalytic reactions. Appl. Catal. A Gen. 1996, 147, 1-21. [CrossRef]

44. Lovell, E.; Horlyck, J.; Scott, J.; Amal, R. Flame spray pyrolysis-designed silica/ceria-zirconia supports for the carbon dioxide reforming of methane. Appl. Catal. A Gen. 2017, 546, 47-57. [CrossRef]

45. Farges, F.; Brown, G.E.; Rehr, J.J. Coordination chemistry of Ti(IV) in silicate glasses and melts: I. XAFS study of titanium coordination in oxide model compounds. Geochim. Cosmochim. Acta 1996, 60, 3023-3038. [CrossRef] 
46. Li, K.; Gao, S.; Wang, Q.; Xu, H.; Wang, Z.; Huang, B.; Dai, Y.; Lu, J. In-Situ-Reduced Synthesis of Ti ${ }^{3+}$ Self-Doped $\mathrm{TiO}_{2} / \mathrm{g}-\mathrm{C}_{3} \mathrm{~N}_{4}$ Heterojunctions with High Photocatalytic Performance under LED Light Irradiation. ACS Appl. Mater. Interfaces 2015, 7, 9023-9030. [CrossRef] [PubMed]

47. Liu, M.; Qiu, X.; Miyauchi, M.; Hashimoto, K. Cu(II) Oxide Amorphous Nanoclusters Grafted Ti ${ }^{3+}$ Self-Doped $\mathrm{TiO}_{2}$ : An Efficient Visible Light Photocatalyst. Chem. Mater. 2011, 23, 5282-5286. [CrossRef]

(C) 2019 by the authors. Licensee MDPI, Basel, Switzerland. This article is an open access article distributed under the terms and conditions of the Creative Commons Attribution (CC BY) license (http://creativecommons.org/licenses/by/4.0/). 